\title{
Comunicação
}

[Communication]

\section{Produção e composição do leite de ovelhas Santa Inês e mestiças Lacaune e Santa Inês e desenvolvimento de seus cordeiros}

\author{
[Milk production and composition of Santa Inês and Lacaune x Santa Inês crossbred ewes and \\ performance of their lambs]
}

\author{
M.I.C. Ferreira ${ }^{1}$, I. Borges ${ }^{2}$, G.L. Macedo Junior ${ }^{3}$, N.M. Rodriguez ${ }^{2}$, C.F.A.M. Penna ${ }^{2}$, M.R. Souza ${ }^{2}$, \\ M.G.T. Gomes ${ }^{4}$, F.A. Souza ${ }^{2}$, L.F. Cavalcanti ${ }^{2}$ \\ ${ }^{1}$ EMBRAPA Caprinos e Ovinos \\ ${ }^{2}$ Escola de Veterinária - UFMG - Belo Horizonte, MG \\ ${ }^{3} \mathrm{UFU}$ - Uberlândia, MG \\ ${ }^{4}$ UFTO - Tocantins, TO
}

Na ovinocultura, a raça Santa Inês, amplamente explorada no território brasileiro, possui índices de produção compatíveis com sistemas europeus de exploração leiteira (Susin et al., 2005), e o bom desempenho de animais na fase de cria está diretamente relacionado com a produção de leite das mães (Peeters et al., 1992). A raça Lacaune tem sua origem atrelada à produção de animais de boa carcaça em diversas regiões da França e passou por um programa de melhoramento genético que resultou em aumento da produção de leite e melhora da composição da carcaça dos cordeiros destinados ao abate (Barillet et al., 2001).

O presente trabalho teve o objetivo de avaliar a produção e a composição do leite de três genótipos de ovelhas - Santa Inês, $1 / 2$ Lacaune $x$ $1 / 2$ Santa Inês e $3 / 4$ Lacaune x $1 / 4$ Santa Inês - e o desenvolvimento de seus cordeiros durante os quatro primeiros meses de lactação.

Os ensaios experimentais foram realizados entre abril de 2006 e novembro de 2007. Foram formados três grupos distintos, de acordo com o genótipo das ovelhas, e, para homogeneizar os grupos, optou-se por trabalhar com fêmeas gestantes de apenas um feto, o que foi acompanhado pelos exames ultrassonográficos realizados nas fazendas de origem dos animais. Foram utilizadas 12 ovelhas de cada genótipo. Os animais foram mantidos em baias individuais

Recebido em 19 de janeiro de 2011

Aceito em 17 de março de 2011

E-mail: mariaizabel@cnpc.embrapa.br no solo desde uma semana antes da data prevista do parto até o final do período experimental, aos quatro meses pós-parto. O presente estudo possui o certificado de aprovação pelo Comitê de Ética Animal (Protocolo número 201/08).

As dietas foram calculadas de acordo com as recomendações do Nutrient... (1985) para consumo de matéria seca (CMS), energia (em nutrientes digestíveis totais, NDT) e proteína bruta (PB), considerando-se o período de lactação e o peso das ovelhas.

Semanalmente, pela manhã, foi mensurada a produção de leite por ordenha manual completa de cada animal. Para garantir o armazenamento significativo do leite na glândula mamária, os cordeiros foram separados das mães na noite anterior ao dia da ordenha, permitindo-se que fosse feita a coleta de leite referente a 16 horas de secreção. O volume individual obtido foi mensurado em uma proveta de $1000 \mathrm{~mL}$ e, posteriormente, ajustado para produção em 24 horas multiplicando-se pelo fator de correção de 1,5 (McKusick et al., 2002). Para a remoção de todo o conteúdo de leite presente nas cisternas da glândula mamária, foi aplicado $0,1 \mathrm{~mL}$ de oxitocina, na concentração de $10 \mathrm{UI} / \mathrm{mL}$, na veia mamária epigástrica, logo após a colocação da ovelha na plataforma de ordenha e imediatamente antes da sua preparação.

Uma alíquota de $200 \mathrm{~mL}$ de leite foi coletada de cada animal após a ordenha e enviada resfriada 
ao laboratório para avaliação de sua composição. Analisaram-se as porcentagens de gordura (Gerber), proteína (Kjeldahl), e extrato seco total (EST - gravimétrico) e desengordurado (diferença entre EST e gordura), de acordo com o método proposto por BRASIL (2003).

O desempenho dos cordeiros foi monitorado quinzenalmente, nos períodos da tarde, a partir dos 15 dias de idade, pela biometria e pelo acompanhamento do ganho de peso. A avaliação biométrica era feita com o auxílio de uma fita métrica e de um hipômetro, sempre com o animal em estação. As medidas avaliadas foram: altura da cernelha, altura do ílio, comprimento corporal, perímetro torácico, largura de peito, comprimento de paleta, largura de paleta, comprimento de pernil, largura de pernil, comprimento de garupa e largura de garupa.

Utilizou-se delineamento inteiramente ao acaso em arranjo fatorial $3 \times 16$ - três genótipos e 16 épocas de mensuração - para a avaliação do leite, e $3 \times 7$ - três genótipos e sete épocas de mensuração - para a avaliação dos cordeiros. Os grupos experimentais foram avaliados utilizandose o teste de comparações múltiplas (SNK) a 5\% de significância. Todos os dados experimentais gerados foram analisados pelo SAEG 9.0" (Sistemas... 2007).

O efeito da interação genótipo versus estádio de lactação não foi significativo $(\mathrm{P}>0,05)$ para a produção de leite. As produções foram diferentes $(\mathrm{P}<0,05)$ segundo o genótipo estudado e a maior média registrada foi a dos animais $1 / 2$ Lacaune, 1550,8mL/dia, seguida da produção dos genótipos 3/4 Lacaune, 1337,6mL/dia, e Santa Inês, $1005,6 \mathrm{~mL} / \mathrm{dia}$.

O incremento de $50 \%$ sobre a produção de leite dos animais puros da raça Santa Inês está de acordo com o relatado por Berger e Thomas (1997), ao trabalharem com cruzamentos entre as raças Lacaune, Dorset e Polypay, quando observaram a mesma variação na produção dos animais F1. Esse fato sugere a melhora obtida com o cruzamento de raças mais produtivas com raças nativas. A boa produção dos animais do genótipo 1/2 Lacaune justifica a sua utilização nos sistemas de criação de ovinos em que se objetiva o aumento da produção leiteira.

Embora a média de produção diária verificada para animais da raça Santa Inês, 1,00L/dia ou $1,06 \mathrm{~kg} /$ dia, tenha sido menor que a encontrada por Susin et al. (2005), 1,50kg/dia, e por Araujo (2006), 1,70kg/dia, os quais também trabalharam com animais Santa Inês, no Brasil, ainda assim se verifica o moderado potencial de produção de leite da raça Santa Inês, como descrito por Susin et al. (2005).

Na Fig. 1, representam-se as médias de produção de cada genótipo ao longo da lactação e a produção acumulada e corrigida ao longo do mesmo período. O padrão de variação das curvas dos três genótipos estudados é semelhante e está de acordo com os padrões de produção de animais de aptidão leiteira (Barillet et al., 2001; Pulina e Nudda, 2002).

Não houve efeito da interação genótipo versus semana em lactação $(\mathrm{P}>0,05)$ para composição do leite, mas observou-se efeito de genótipo sobre os constituintes do leite $(\mathrm{P}<0,05)$. Os percentuais de gordura e proteína foram mais altos $(\mathrm{P}<0,05)$ no leite de animais Santa Inês, $6,6 \%$ e $5,1 \%$, respectivamente, seguidos pelos dos genótipos $1 / 2$ Lacaune, 4,6\% para gordura e 4,3\% para proteína, e 3/4 Lacaune, 4,4\% para gordura e $4,1 \%$ para proteína. O padrão de produção observado para gordura e proteína, inverso ao seguido pelo volume de leite produzido ao longo da lactação, exemplifica o efeito da diluição dos constituintes do leite em função do volume produzido (Nudda et al., 2002).

O genótipo $1 / 2$ Lacaune apresentou as maiores médias $(\mathrm{P}<0,05)$ para EST, 209,81g. A composição do leite pode estar relacionada à manifestação do potencial produtivo da raça Lacaune. Esse fato pode ser vantajoso ao se considerarem os sistemas de exploração do leite ovino, com leite de melhor qualidade para a indústria. 


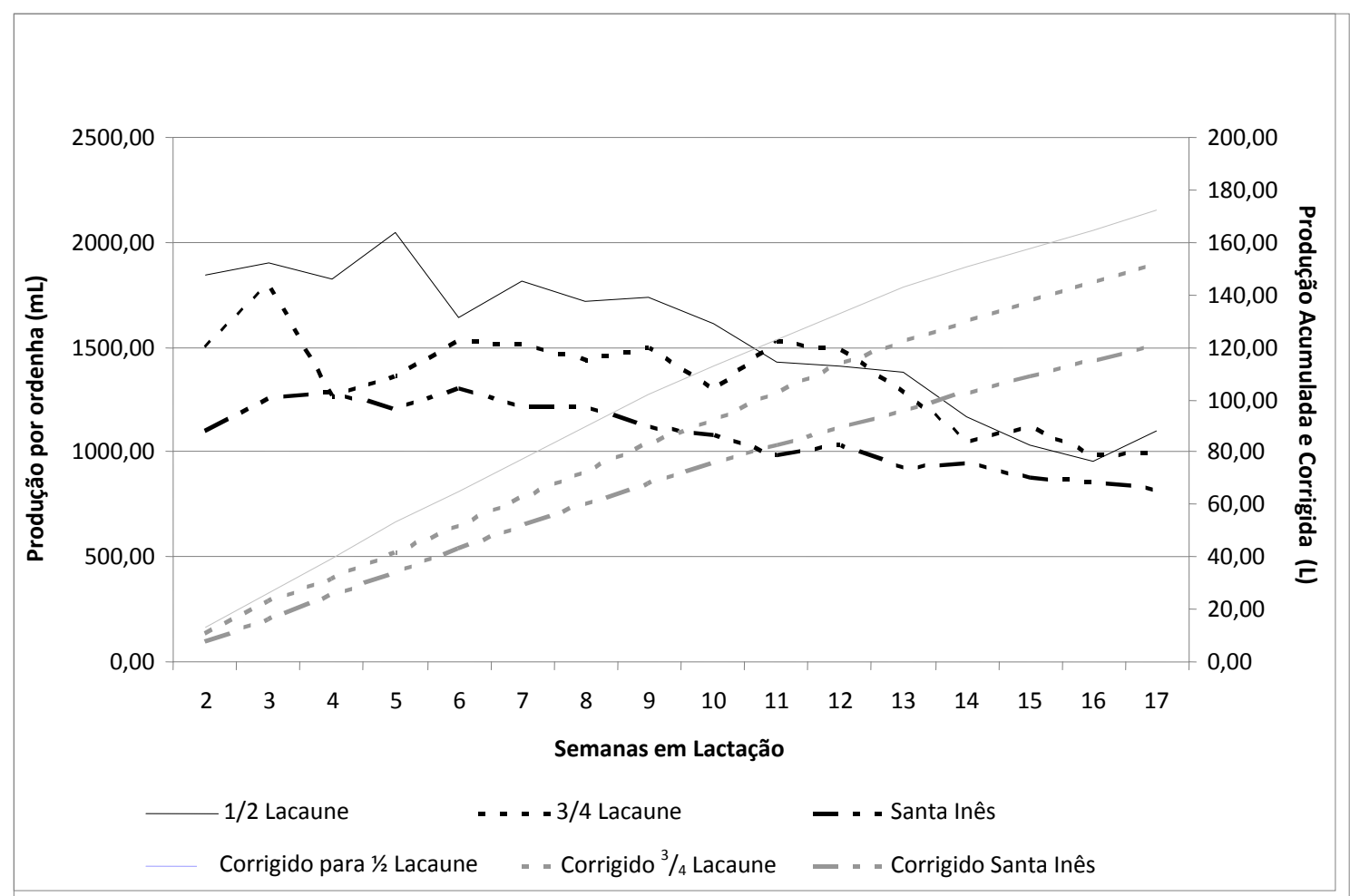

Figura 1. Produção de leite de ovelhas de acordo com o genótipo estudado em relação às semanas em lactação e às médias acumuladas para todo o período de lactação.

Houve efeito $(\mathrm{P}<0,05)$ da interação genótipo versus a idade do cordeiro para os dados biométricos de comprimento da garupa e perímetro do pernil. Para o comprimento de garupa, o melhor resultado ocorreu $(\mathrm{P}<0,05)$ com os animais Santa Inês aos 15 dias de idade. A partir daí, essa superioridade não mais existiu $(\mathrm{P}>0,05)$ para os três genótipos até os 75 dias de idade das crias. Aos 90 e aos 105 dias de idade dos cordeiros os resultados foram semelhantes $(\mathrm{P}>0,05)$ entre os cruzados e mais altos $(\mathrm{P}<0,05)$ para os puros Santa Inês. Os animais mestiços apresentaram crescimento otimizado em função da idade e foram capazes de melhorar a conformação do posterior, com maior deposição de massa corpórea na garupa, enquanto o desenvolvimento dos cordeiros puros Santa Inês não foi diferente $(\mathrm{P}>0,05)$ nas idades mensuradas.

Em relação ao perímetro do pernil, em função do genótipo, os animais Santa Inês foram semelhantes aos mestiços $(\mathrm{P}>0,05)$ dos 15 aos 45 , aos 90 e aos105 dias de idade, e foram superiores $(\mathrm{P}<0,05)$ entre 60 e 75 dias de idade. Em função da idade, o genótipo Santa Inês apresentou crescimento contínuo $(\mathrm{P}<0,05)$ até os 60 dias de idade, quando, então, houve desaceleração do desenvolvimento, enquanto os animais mestiços não apresentaram a mesma diferença significativa. Desse modo, percebe-se que, para a deposição de carne no pernil de cordeiros, o fator idade prevalece sobre 0 genótipo.

Para as mensurações biométricas perímetro torácico (PT), largura de peito (LP), largura de garupa (LG), comprimento de paleta (Cpal) e comprimento de pernil (CP) houve efeito isolado do genótipo $(\mathrm{P}<0,05)$. Para estes parâmetros, observa-se a superioridade das crias dos genótipos mestiços em relação ao genótipo Santa Inês $(\mathrm{P}<0,05)$. Este fato talvez retrate a aptidão para a produção de carne da raça Lacaune (Barillet et al., 2001). Aos 90 dias de idade, os cordeiros apresentaram desaceleração do crescimento e atingiram o peso vivo de abate preconizado pelos frigoríficos no Brasil, $30 \mathrm{~kg}$.

Palavras-chave: ovelha leiteira, lactação, biometria 


\begin{abstract}
The effects of three maternal genotypes were evaluated on sheep milk production and composition, and on performance of their lambs during the first four months of age. The work was developed with Santa Inês and Lacaune x Santa Inês crossbred ewes. The average milk production was: 1/2 Lacaune, 1,550.8mL/day; 3/4 Lacaune, 1,337.6mL/day; and Santa Inês, 1,005.8mL/day. There was an effect of genotype on some constituents of milk (fat and protein). For the performance of the lambs, there was an effect of maternal genotype $(P<0.05)$ on the following biometric measurements: chest circumference, width of chest, width of rump, length of the shoulder length of leg, and perimeter of shank.
\end{abstract}

Keywords: sheep milk, lactation, biometry

\section{REFERÊNCIAS BIBLIOGRÁFICAS}

ARAUJO, R.C. Produção de leite e atividade ovariana pós-parto de ovelhas Santa Inês alimentadas com casca de soja em substituição ao feno "coastcross" (Cynodon SP.). 2006. 137f. Dissertação (Mestrado) - Escola Superior de Agricultura "Luiz de Queiroz” Piracicaba, SP.

BARILLET, F.; MARIE, C.; JACQUIN, M. et al. The French Lacaune dairy sheep breed: use in France and abroad in the last 40 years. Livest. Prod. Sci., v. 71, p.17-29, 2001.

BERGER, Y.M.; THOMAS, D.L. Early experimental results for growth of East Friesian crossbred lambs and reproduction and milk production of East Friesian crossbred ewes. In: GREAT LAKES DAIRY SHEEP SYMPOSIUM, 3., 1997, Madison. Proceedings... Madison: [s.n.], 1997. p.17-26.

BRASIL. Ministério da Agricultura Pecuária e Abastecimento. Instrução Normativa $n^{\circ} 22$, de 14/04/2003. Métodos analíticos oficiais físicoquímicos para controle de leite e produtos lácteos. Brasília: Ministério da Agricultura, 2003.

McKUSICK, B.C.; THOMAS, D.L.; BERGER, Y.M. et al. Effect of milking interval on alveolar versus cisternal milk accumulation and milk production and composition in dairy ewes. $J$. Dairy Sci., v.85, p.2197-2206, 2002.
NUDDA, A.; BATTACONE, G.; BENCINI, R. et al. Nurition and milk quality. In: PULINA, G. (Ed.). Dairy sheep feeding and nutrition. 2.ed. Bologna: Avenue Media, 2002. Cap. 8., p.197228.

NUTRIENT requirements of sheep. 6. ed. Washington, DC: National Research Council, 1985. $99 \mathrm{p}$.

PEETERS, R.; BUYS, N.; ROBIJNS, L. et al. Milk yeld and milk composition of Flemish Miksheep, Suffolk and Texel ewes and their crossbreds. Small Ruminant Res., v.7, p.279-288, 1992.

PULINA, G.; NUDDA, A. Milk production. In: PULINA, G. (Ed.). Dairy sheep feeding and nutrition. 2.ed. Bologna: Avenue Media, 2002. Cap.1., p.11-28.

SISTEMAS para análise estatística e genética SAEG. Versão 9.0. Viçosa: UFV, 2007.

SUSIN, I.; PIRES, A.V.; MENDES, C.Q. et al. Milk yield and milk composition of Santa Ines ewes. In: JOINT ADSA-ASAS-CSAS ANNUAL MEETING, 2005, Cincinnati, OH, USA. J. Anim Sci., v.83, p.86, 2005. 